\title{
Research on Employment of Poor Labor Force of Minorities of Rural Southern Xinjiang
}

\author{
Jia Nannan, Wang Pengcheng \\ College of economics and management Tarim University Alar Xinjiang 843300, China
}

Keywords: Southern Xinjiang, Minorities, Poor labor force, Employment.

\begin{abstract}
With the implementation of Western Development and strong national support of Xinjiang, the social economy in Xinjiang area has made great progress, and the employment level of the whole province has been greatly improved, but it is not optimistic in the employment status of poor labor among rural minorities. The three prefectures in Southern Xinjiang are one of the destitute areas in China, and the employment of poor labor force in many poor counties has been a major cause for the poverty of Southern Xinjiang. Therefore, this paper mainly studies the employment of poor labor force in rural minorities in Southern Xinjiang, hoping to provide references for the employment of poor labor force in rural minorities of Southern Xinjiang and to promote the further development of social economy in Xinjiang.
\end{abstract}

\section{Introduction}

With the reform and opening up, China's rural labor force has presented the continuous and large-scale flow to towns and counties across the regions, which has increased the income of the farmers and driven regional economic development while promoting the industrialization and agricultural modernization. However, it is relatively backward in the non-agricultural economic development in less developed areas, such as Xinjiang, and the poor labor force in rural areas cannot flow out and it is difficult in transfer employment, puzzling the social and economic development in Xinjiang and other areas, and the poverty alleviation of farmers. It is urgent for the current Xinjiang to solve the difficulties in transfer employment of poor labor force in rural areas to promote the rural poor households to overcome poverty.

Empirical research shows that due to the small endowment of resources in poor areas, migrant workers can significantly increase income and alleviate poverty. The problem of poor labor force of rural minorities in Southern Xinjiang is similar to that of general migrant workers, but it also has its characteristics. Influenced by such factors as history, culture and humanistic environment, rural labor mobility in Southern Xinjiang has its unique regional and cultural brand. Due to language and customs and limitations of their own quality, most of minority labor force chooses to work in Xinjiang while cross-regional mobility is relatively small. This paper discusses and finally solves the employment problem of the poor labor force in rural areas of Southern Xinjiang, which will exert an important impact on increasing farmers' income in Xinjiang, assisting farmers in Southern Xinjiang in getting out of poverty, narrowing the regional economic gap between the north and the south of Xinjiang and realizing the general objective for social stability and prolonged political stability in Xinjiang.

\section{Analysis in the status of transfer employment for poor labor force in rural areas of Southern Xinjiang}

The international academic circles have various theoretical explanations, among which the most famous is the Push and Pull Theory by E.G .Ravenstein et al, which believes that the population mobility is generated in the combined effect of "push" and "pull". After that, on the basis of Push and Pull Theory, E.S.Lee supplemented the third factor of "intervening obstacles", which considers that population mobility is the result of the combination of these three factors. For the outflow of 
the poor labor force of rural minorities in Southern Xinjiang, people mostly have no choice but to flow out by force of life pressure but they don't have strong will to improve the living conditions, so that it is almost consistent with the results of three factors proposed by E.S.Lee. The distance, material guarantee, language, culture, religion, customs, transfer cost, employment concept and other factors are the key factors to hinder the transfer of poor labor force of rural minorities in Southern Xinjiang, while education, health, employment, population and regional characteristics have impact on poverty. Therefore, the research on the transfer employment of poor labor force of rural minorities in Southern Xinjiang should be based on universality and pay attention to the study and consideration of its particularity.

Differences of minority culture mainly lie in the great differences in religious beliefs, customs, language and culture. The poor labor force of rural minorities is greatly different from that of the inland in religious belief, customs and customs, language and culture. The poor labor force in rural Southern Xinjiang is restricted by its own ethnic culture and there is a small range of employment suitable for them, which has become a major problem of the employment.

When the poor labor force of rural minorities leaves the land and is engaged in non-agricultural labor, they are badly in need of non-agricultural skills to increase human capital, but it is lagging in the occupation training dominated by technical education, and the government has inadequate investment in employment training, and then the lack of capacities becomes a threshold for the employment of the rural poor labor force. With the low basic educational level, most of the rural poor workers are not divorced from traditional manual labor while the industry is still dominated by the primary industry, and they fail to concentrate on developed cities of industry and commerce. The poor labor force of rural minorities has low cultural quality so that there is hardly any supporting force to get rid of poverty.

There is a high birth rate in the minorities of Southern Xinjiang, ranking top in China, while there is a trend of continuing to increase. The decreasing land resources, the less farmland per capital, and the prominent contradiction between more population and less land, the limited capacity of agriculture and increase in labor supply have led agricultural production to be insufficient to admit more labor resources, so that it is low in the level of economic income. In accordance with exchanges, the poor labor force of rural minorities mostly has no choice but to transfer outward by force of life pressure, rather than actively flow out to change the unfavorable living conditions.

Restricted by the regional drought, Southern Xinjiang has slow urbanization on the oasis and limited capacity to arrange for the poor labor force in rural areas, while there are docking obstacles between the posts for labor employment in industrialization and the needs for labor posts. It is high in consumer expenditure in urban areas, but the rural poor labor force has low wage levels in urban areas, and the ratio of urban and rural consumer expenditure has increased, which will increase the consumption expenditure of rural labor transfer in poverty, thus hindering the transfer of the rural poor labor force to urban areas.

As an important variable of spatial poverty, geographical location determines the advantages and disadvantages of the access to infrastructure, policy support and other advantages, which has a significant impact on poverty reduction. Since Southern Xinjiang is far away from the inland provinces, and thousands of kilometers away from the eastern coastal areas, it is high in travelling expenses and difficult to take account of the households, so that the poor labor force in rural areas prefer to choose transfer employment within Xinjiang.

In Southern Xinjiang, a great deal of poor labor force in rural areas holds the obsolete and conservative ideas of "Preferring to hold the small piece of land in the hometown, rather than thinking of the large piece of land in an alien land", lacks hard-working spirit and has the idea of "waiting, depending and wanting", and they are picky on the posts and labor discipline needs to be improved, reducing the enterprise's employment intention. The poor labor force of rural minorities is used to communicating in their mother tongue, and has differences with the residents in the places of the inflow in living style and habits, so that the residents in their inflowing place will form stereotypes on them, leading to the lack of social belongingness of the poor labor force of rural 
minorities.

\section{Suggestions on employment path for the rural labor force in poverty in Southern Xinjiang}

The transfer of the poor labor force of rural minorities from traditional agriculture to nonagricultural industries, from rural to urban areas is an important way for the minority settlement to overcome poverty precisely and the inevitable course to realize industrialization, modernization and urbanization. At present, it tends to be mild in the transfer speed and scale of poor labor force in rural Southern Xinjiang, and the difficulty of transferring is gradually increasing, so that it is necessary to find a new way to transfer the rural poor labor force and get rid of poverty.

To strengthen the government's employment guidance to the rural labor force. The transfer employment of the rural poor labor force is an important starting point for farmers in minority settlements to overcome poverty and increase income, so the party and government departments at all levels should take the initiative to make achievements. Especially for the farmers in strong willingness to transfer but without travelling expenses, the government should take them as the focus of labor transfer, increase financial support and continue to transfer the rural poor labor force through the strategy of "supporting a group and driving a group". It should introduce various preferential policies according to local conditions, and fully motivate the enthusiasm of laborintensive enterprises to employ and train local farmers according to the characteristics of the rural labor force in minority areas who has low educational background and difficulties in off-site transfer employment, striving to promote the local and nearby transfer employment of poor labor force in rural areas. The government should take minority areas as the main battlefield of the transfer of employment, highlight organizational promotion, and increase the information service for farmers' employment, policy support and coordination efforts, so as to make greater progress in the transfer employment of rural labor force in poverty in minority areas.

To try to tap income-generating potential of rural labor force. First, we must comprehensively increase agricultural employment and increase income. We should adjust and optimize the agricultural structure, support and develop new subjects of agricultural operation and moderate scale management of the land in various forms, guide and encourage farmers to do work for large professionals and cooperatives based on completing their own contractual management on household basis. Second, we should give full support to labor-intensive industries to absorb the rural labor force. Moreover, we should continue to strengthen government support, allow the government to arrange training subsidies for targeted posts and allow the enterprises to apply subsidies for migrant workers, to accelerate the development of labor-intensive industries in great employment capacity. And then we should continue to organize and participate in infrastructure construction. Furthermore, we should organize and guide local farmers to participate in the settlement of the rich people nearby, local disease prevention, water improvement, irrigation and water conservancy, highway and railway and other infrastructure construction. Finally, we should strengthen the integration and cooperation in the labor services between the corps and local authorities, consolidate the docking with the corps in employment information, and guide more rural labor force to work and create income in the corps and support the labor-intensive enterprises in Northern Xinjiang to take the initiative to employ the poor labor force of rural minorities in Southern Xinjiang.

To increase the transfer of poor labor force in Southern Xinjiang outwards Xinjiang. The transfer employment to the inland will not only increase the income of the farmers, but also promote the quality of the farmers, broaden the horizons of the farmers, change the ideological concepts of farmers, and promote ethnic exchanges and blending, which is required to make longterm and firm progress. We should enhance the level of understanding of poor labor force of rural minorities to work and engage in business in the inland, try to overcome difficulties, consolidate the existing employment channels, and go to the countryside for detailed propaganda and education to farmers, and lead the farmers' ideologies to transform from that "I should to go out to work" to that "I want to go out to work", forming a demonstration effect. The government should set up a coordination mechanism for labor service export with the partner provinces and cities in assisting 
Xinjiang, formulate more preferential policies and measures, and implement the subsidy policy for the transportation costs in transfer employment outwards Xinjiang. Meanwhile, it should establish organizations for transfer employment services, and explore the preferential policies for inland enterprises to employ workers from Xinjiang, so as to increase the enthusiasm of enterprises to receive employees.

To establish a long-term employment mechanism in line with the actual situation. First, we should improve the quality of rural labor force. Based on the basic education, we should strengthen the education and training of farmers, and make great efforts in the rural compulsory education, bilingual education and education of practical employment skills in secondary vocational and technical schools, develop targeted skill training on agricultural skills and job skills, focus on the training of communication skills in Chinese for migrant workers and actively carry out the training of farmers' entrepreneurial ability. Moreover, we should support the surplus labor in rural households who fails to receive higher education after middle school to work in factories. Second, we should pay attention to guiding farmers to change their employment concept, vigorously promote the public conducts that labor is glorious and respected, abandon wrong concepts of taking the occupation to assess superiority or inferiority and taking the post to assess whether it is good or bad, abolish the traditional constraints of the old thoughts and assist farmers in establishing the ideas of independent employment to reflect values. We should encourage farmers, especially the new generation of young farmers, to "go out" and work in where it is rich and developed with many opportunities of employment, so as to broaden their horizons, increase their knowledge, and gather the experience to improve their capacities to make a living. Third, we should form a mechanism of employment security for urban and rural integration as soon as possible, actively explore the promotion of the reform of the rural domiciliary control system, employment system, compulsory education system and social security system in the development of urban and rural integration, and support farmers to transfer to county towns and to converge in central towns, accelerate the construction of employment information service system in urban and rural integration, and promote the fair employment between urban and rural labor. Fourth, we should steadily carry forward the citizenization of migrant workers, optimize the policy environment, solve the worries of farmers in transfer, guide qualified farmers to settle down in the employment place, and transform from farmers to urban inhabitants and achieve a fundamental change in the status of farmers.

\section{Acknowledgments}

Fund Project: the General National Social and Science Project - the Circum-Tarim Regional Economic Coordination and Development Research (Project No. 12BJL084)

\section{References}

[1] Zhang Ran, Li Jigang. Research on Employment of Minority Labor Force in Xinjiang [J]. Xinjiang State Farms Economy, 2014 (07): 81-84.

[2] Chen Wan. Research on Transfer Employment of Minority Labor Force in Poor Towns of Qapqal County [D]. Xinjiang Agricultural University, 2013.

[3] Ma Jinli. Analysis of Countermeasures about Transfer of Surplus Rural Labor in Minority Areas-Take Qira County of Xinjiang as an Example [J]. Tribune of Social Sciences in Xinjiang, 2017 (01): 21-24.

[4] Yang Xuemei, Zhang Zongmin. Status, Problems and Countermeasures about Employment of Surplus Rural Labor in Minority Areas [J]. Indian Ocean Economic and Political Review, 2005 (02): 104-105.

[5] Yipare Yiming. Research on Transfer Employment of Surplus Rural Labor in Minority Areas in Xinjiang-Take S County in Kashi Prefecture as an Example [D]. East China University of Science and Technology, 2012. 